\title{
Multiple Impacted Teeth: Report of 3 Cases
}

Gürkan Rașit Bayara, DDS, PhD

Kerim Ortakoḡlub, DDS, PhD

Metin Sencimenc, DDS, PhD

\begin{abstract}
While impaction of tooth is widespread, multiple impacted teeth by itself is a rare condition and often found in association with syndromes such as cleidocranial dysplasia or Gardner's syndrome. A light of radiographic examination, we describe three Turkish young males with multiple impacted teeth who didn't possess any systemic conditions or syndromes involving both jaws. The first patient, a 21 -year-old young male, had 16 unerupted teeth and 5 unerupted supernumerary teeth. The second patient with totally edentulous mandible, a 20 -year-old young male, had 31 unerupted teeth. The third patient, a 21 -year-old young male, had 22 unerupted teeth and 4 unerupted supernumerary teeth. Based on the clinical presentation, radiographic examination and histopathological studies, this paper discusses the differential diagnosis and management of such cases. (Eur J Dent 2008;2:73-
\end{abstract} 78)

Key words: Impacted teeth; Cleidocranial dysplasia; Gardner's syndrome; Supernumerary teeth.

\section{INTRODUCTION}

Impaction of teeth can result firstly from local biomechanical impediments, and secondarily from childhood maxillofacial or dentoalveolar

- a Department of Oral and Maxillofacial Surgery, Dental Clinic, Guzelyali Military Hospital, Izmir, Turkey.

b Associate Professor, Department of Oral and Maxillofacial Surgery, Dental Sciences Center, Gülhane Military Medical Academy, Etlik, Ankara, Turkey.

Assistant Professor, Department of Oral and Maxillofacial Surgery, Dental Sciences Center, Gülhane Military Medical Academy, Etlik, Ankara, Turkey.

- Corresponding author: Metin Sencimen

Gulhane Military Medical Academy Department of Oral and Maxillofacial Surgery PB: 06018 Etlik\Ankara\Turkey

Phone: +903123046069

E-mail: metinsencimendyahoo.com trauma, reconstructive surgery of the facial skeleton, malpositioning of an adjacent tooth, thickened overlying osseous or mucosal tissues, insufficient maxillofacial skeletal development or a low correlation between maxillofacial skeletal development and tooth maturation, eruption disturbances and owing to direct or indirect effects of cysts or neoplasm. ${ }^{1}$ A host of systemic prenatal and postnatal disorders, diseases and syndromes (Table 1)1,2 can also cause tooth impaction. Therefore, it is prudent to perform a thorough clinical examination and obtain adequate radiographs when teeth do not appear according to the usual eruption schedule. ${ }^{1}$

The purpose of this article is to present 3 cases with multiple impacted teeth in which no syndrome or systemic conditions have been detected involving both jaws. 


\section{CASE REPORTS}

\section{Case 1}

In 2000, 21 year old male patient referred to our clinic with respect to the failure of eruption of the upper and lower anterior teeth. In his medical history, it was detected that he was born at 39 weeks gestation to a 29 year-old mother and a 33 year-old father. The pregnancy and delivery were normal and his birth weight was approximately 3.1 $\mathrm{kg}$.

During the clinical examination at the age of 21 , a height of $152 \mathrm{~cm}$ and a weight of $55 \mathrm{~kg}$ were registered. The circumference of the head were measured as $57 \mathrm{~cm}$. None of these measurements deviated from the norm. Facially, he had a broad, flat, fleshy nose. His ears were thick and floppy. Despite the fact that the examination of the hands showed normal findings, the examination of the feet showed that the nails of his toes were hypoplastic bilaterally and the third toes were rudimentary. In addition, congenital curly (or varus) toe was noted that on left foot's fourth and fifth toes and right foot's fifth toe and was also noted that hammer toe on both of feet's toes were apart from first toes. No other family members were known to have similar abnormalities of the hands and feet. Radiological evaluations of the clavicles, vertebral skeleton, skull and chest proved to be normal. Ophthalmological and neurological examination of the patient revealed no pathological symptoms. Intelligence was subjectively normal. There was no pes cavus. A joint hypermobility involving the metatarsophalangeal and knee joints was noted. Liver and spleen were not palpable. The skin was dry, soft and velvety. Head hair and body hair were clinically normal but his eyebrows were thick and bushy. Results of routine hematology tests and karyotyping $(46, X Y)$ were normal.

During the intraoral examination of the patient, the oral soft tissues were unremarkable and histopathological evaluations of gingivae were normal. The patient was found to be in the permanent dentition phase with the following teeth being fully erupted (Figure 1):

\begin{tabular}{c|l}
1715145352 & 626324252627 \\
\hline 468583 & 7273753638
\end{tabular}

Maxillary right permanent primary molar, mandibular right permanent second molar and mandibular left permanent second molar were extracted because of caries. Mandibular right and left permanent central incisor, mandibular right and left second premolar were partially erupted. The following teeth were unerupted:

\begin{tabular}{l|l}
18131211 & 21222328 \\
\hline 48444342 & 32333435
\end{tabular}

Table 1. Syndromes associated with tooth impaction and hyperdontia., ${ }^{2,21}$

\begin{tabular}{ll}
\hline $\begin{array}{l}\text { Some systemic prenatal and postnatal disorders, } \\
\text { diseases and syndromes causing to tooth impaction }\end{array}$ & Some syndromes associated with hyperdontia \\
\hline $\begin{array}{l}\text { Cleidocranial dysplasia } \\
\text { Gardner syndrome }\end{array}$ & $\begin{array}{l}\text { Apert syndrome } \\
\text { Angio-osteohypertrophy Craniometaphyseal dysplasia }\end{array}$ \\
$\begin{array}{l}\text { Darskog syndrome } \\
\text { Zimmerman-Laband syndrome }\end{array}$ & Crouzon syndrome \\
Noonan's syndrome & Ehler-Danlos syndrome \\
GAPO syndrome & Fabry-Anderson Fucosidosis syndrome \\
Osteoglophonic dysplasia & Hallermann-Streiff syndrome \\
Osteopathia striata & Kippel-Trénaunay-Weber syndrome \\
Osteopetrosis & Nance-Horan syndrome \\
Progeria & Oral-facial-digital syndrome \\
$\begin{array}{l}\text { Singleton-Merten syndrome } \\
\text { Yunis-Varon syndrome } \\
\text { Nonhereditary pathoses such as endocrine disorders } \\
\text { Mucopolysaccharidoses }\end{array}$ & Sturge-Weber syndrome \\
\hline
\end{tabular}


Radiologically, five unerupted supernumerary teeth were also noted. One of them was in the maxillary right posterior region and others were in the maxillary anterior region (Figure 2).

His impacted primary teeth, some of the impacted permanent and supernumerary teeth were removed and it was planned to assist the eruption of other permanent teeth by surgical exposure and orthodontic traction with intermittent monitoring periods. But he didn't continue to the treatment after the end of his military service.

\section{Case 2}

In 2001, 20-year-old male patient referred to our clinic with respect to the failure of eruption of some upper and all lower teeth. In his medical history, it was detected that he was born at 38 weeks gestation to a 41-year-old mother and a 45 year-old father. The pregnancy and delivery were

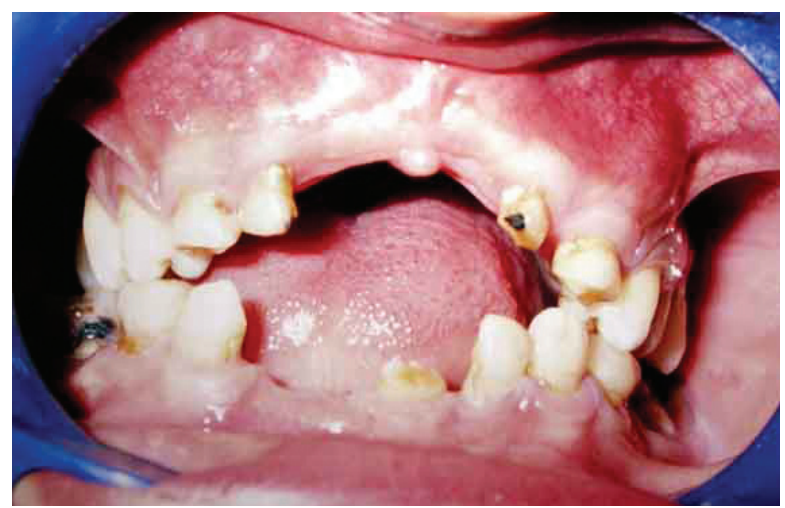

Figure 1. Intraoral view of patient is showing fully and partially erupted teeth and gingivae (Case 1).

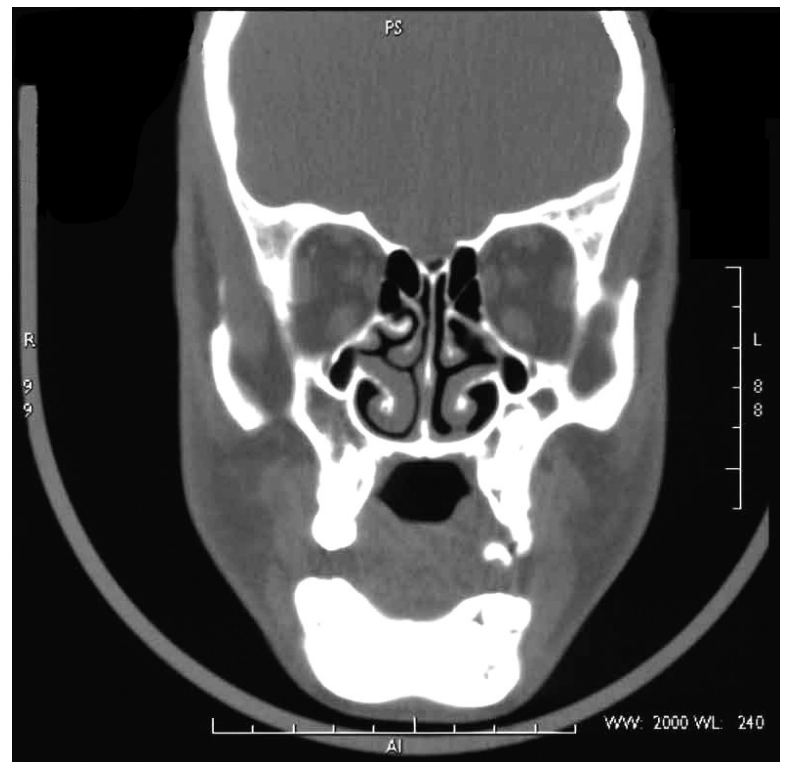

Figure 3. CT scan of paranasal sinus is showing bilaterally frontal sinus agenesis and maxillary sinus hypoplasia (Case 2). normal and his birth weight was approximately $3.150 \mathrm{~kg}$.

During the general examination, a height of $165 \mathrm{~cm}$ and a weight of $55 \mathrm{~kg}$ were registered. The circumference of the head was measured as $49 \mathrm{~cm}$. None of these measurements deviated from the norm. There were epichantus on his eyes and his ear lobes were sticked. Ophthalmological and neurological examination of the patient revealed no pathological symptoms. Intelligence was subjectively normal. Liver and spleen were not palpable. Radiologically, clavicles, vertebral skeleton, chest, skull, hands and feet were normal. CT scan of the paranasal sinus evaluations showed frontal sinus agenesis and maxillary sinus hypoplasia (Figure 3). Results of routine hematology tests and karyotyping $(46, \mathrm{XY})$ were normal. There was no significant medical or dental history of the patient's family.

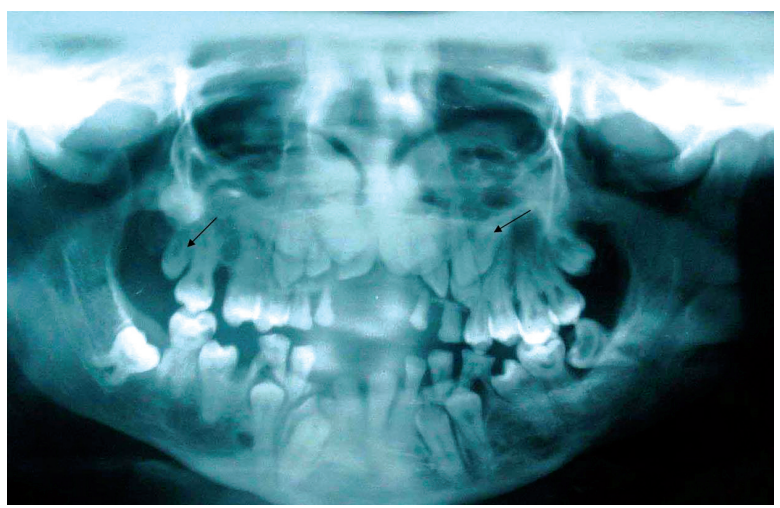

Figure 2. Panoramic radiograph is showing unerupted teeth and supernumerary teeth (marked with arrows) (Case 1).

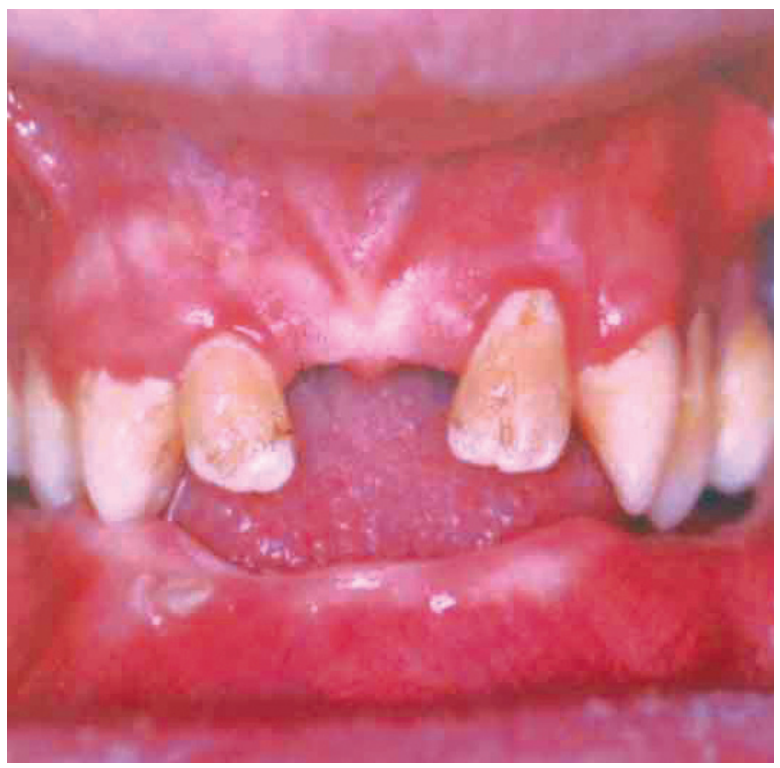

Figure 4. Intraoral view of patient is showing totally clinically edentulous mandible (Case 2). 
Intraoral examination revealed that the patient's maxilla was partially edentulous with the following erupted teeth:

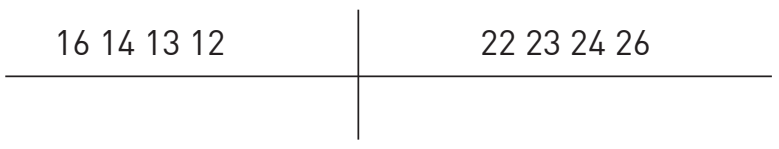

The patient's mandible was clinically edentulous (Figure 4). The panoramic radiograph of the patient demonstrated multiple impacted teeth in maxilla and mandible. Some dental crown-root abnormalities and ectopic teeth were also noted (Figure 5). The following teeth were impacted:

\begin{tabular}{c|l}
18171511 & 21252728 \\
\hline 4746854544834382428141 & 317132723373347435753637
\end{tabular}

The patient stated that, during his childhood, his mandibular right deciduous primary molar tooth erupted but soon decayed and came out. The oral soft tissues were unremarkable and histopathological evaluations of gingiva were normal.

It was planned to remove the impacted primary teeth, some of the impacted permanent teeth and to assist the eruption of other permanent teeth by surgical exposure and orthodontic traction with intermittent monitoring periods. It was also planned to insert six implants in the mandible and to apply implant supported prosthesis.

In the initial phase of the treatment, the patient was taken to the operating room and following induction of general anesthesia, all of the twenty three of impacted teeth in the mandible were removed. After two weeks the patient was taken to the operating room for the secondary phase of the treatment. Maxillary right and left permanent

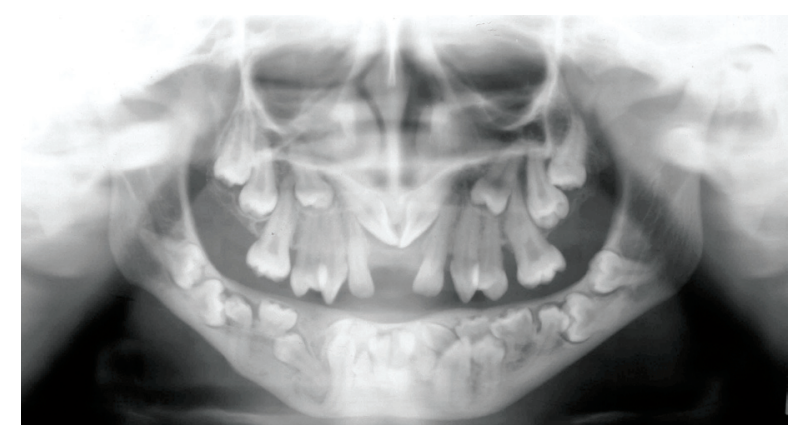

Figure 5. Panoramic radiograph is showing that multiple impacted teeth, ectopic teeth and some dental crown-root abnormalities are in maxilla and mandible (Case 2). second premolars, right and left third molars were removed. The treatments of maxillary right and left permanent central incisors and right and left second molars by surgical exposure and orthodontic traction were started. But he didn't continue to the treatment after the end of his military service.

\section{Case 3}

In 2001, 21-year-old male patient referred to our clinic with respect to the failure of eruption of some upper and all lower teeth. In his medical history, it was detected that his pregnancy and delivery were normal.

During the general examination, a height of $167 \mathrm{~cm}$ and a weight of $70 \mathrm{~kg}$ were registered. The circumference of the head was measured as $52 \mathrm{~cm}$. Despite none of these measurements deviate from the norm, malar hypoplasia was noted facially. Radiologically, clavicles, chest, skull and vertebral skeleton were relatively normal. The radiological evaluations of his hands and feet showed that minimal clinodactyly was on bilaterally fourth and fifth fingers and first and fifth toes. During the radiological examination of the lower extremities coxa valga were registered bilaterally (Left $145^{\circ}$ Right $155^{\circ}$ Normal 120-130'). Ophthalmological and neurological examination of the patient revealed no pathological symptoms. Intelligence was subjectively normal. Liver and spleen were not palpable. Results of routine hematology tests and karyotyping $(46, X Y)$ were normal. There was no significant medical or dental history of the patient's family.

Intraoral examination revealed that the patient's maxilla and mandible were partially edentulous with the following erupted teeth (Figure 6):

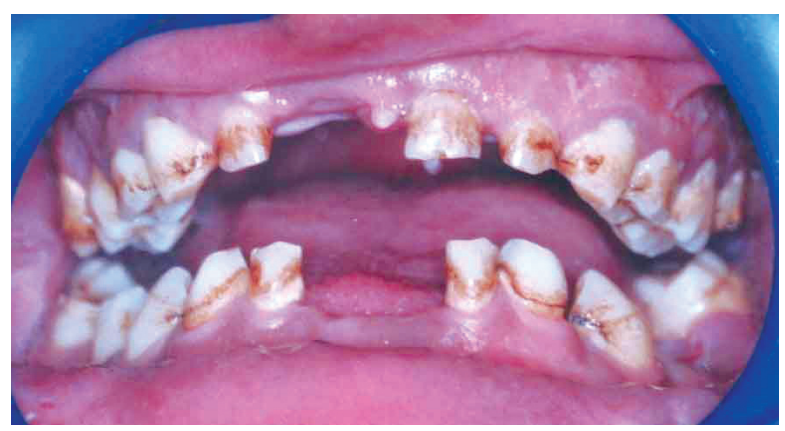

Figure 6. Intraoral view of patient is showing gingivae and erupted teeth (Case 3). 
$171655545352 \quad 61626364652627$

\begin{tabular}{l|l|l}
474645448382 & 72733537
\end{tabular}

The panoramic radiograph of the patient demonstrated multiple impacted teeth in maxilla and mandible (Figure 7). The following teeth were impacted:

\begin{tabular}{r|r}
181514131211 & 212223242528 \\
\hline 48434241 & 313233343538
\end{tabular}

Radiologically, four unerupted supernumerary teeth were also noted. Two of them were in the maxillary and mandibulary left posterior region and others were in the maxillary right posterior region. The oral soft tissues were unremarkable and histopathological evaluations of gingivae were normal.

It was planned to remove the persisted primary teeth, some of the impacted permanent and supernumerary teeth and to assist the eruption of other permanent teeth by surgical exposure and orthodontic traction with intermittent monitoring periods. But he didn't continue to the treatment after the end of his military service.

\section{DISCUSSION}

Multiple impacted teeth by itself is a rare condition and often found in association with syndromes such as cleidocranial dysplasia, ${ }^{2-4}$ Gardner's syndrome, ${ }^{2,5-7}$ Down syndrome, ${ }^{2,7}$ Aarskog syndrome, 2,8 Zimmerman-Laband syndrome $\mathrm{e}^{2,9,10}$ and Noonan's syndrome. ${ }^{2,7}$ Although some other features were discovered on our cases beside multiple impacted teeth, all features of any syndrome couldn't be diagnosed exactly.

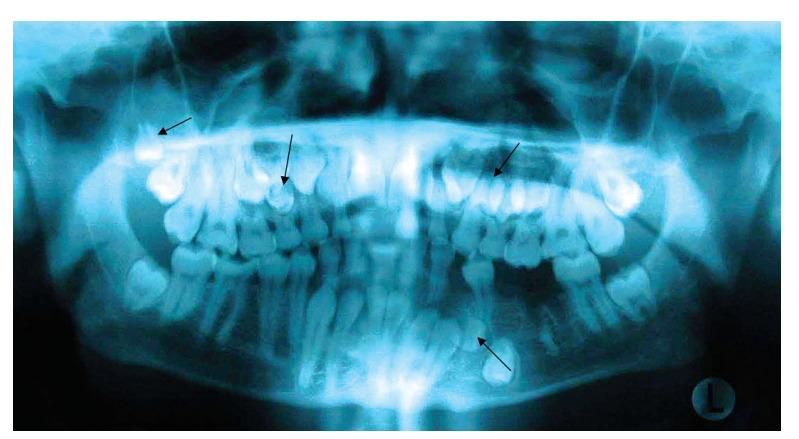

Figure 7. Panoramic radiograph is showing that unerupted teeth and supernumerary teeth (marked with arrows) are in maxilla and mandible (Case 3 ).
Only a few cases of non-syndrome multiple impacted teeth were reported., 3,11-13 Impacted teeth are those which are prevented from eruption by some physical barrier in the eruption path. The oral soft tissues of our cases were unremarkable and histopathological evaluations of gingivae were normal. The clinical and radiographic examinations of our cases revealed relatively normal jaws and teeth despite the fact that some dental crown-root abnormalities were detected on case 2. Abnormalities of tooth morphology are related to inadequate space and arrested eruption. Delayed or arrested eruption is probably caused by diminished resorption of bone and of primary teeth and to the presence of multiple supernumerary teeth. ${ }^{3}$ Conditions which cause lacking of eruptive force in such cases could be due to either general, endocrinal, neurogenic or mucosal and bone disorder. Especially, at the case 2 operation dense compact bone in the mandible was observed. Conditions where we find retained teeth are: hemifacial atrophy, hypopitutarism, hypothyroidism, cherubism, gingival fibromatosis, cleft palate and preceding syndromes. ${ }^{5,7}$ On account of the fact that the medical history of our cases was non-contributory; above conditions were excluded.

Babu et $\mathrm{al}^{3}$ stated that the exact cause and the significance of multiple impacted supernumerary teeth remain an enigma to us. Multiple supernumerary teeth without any associated systemic conditions or syndromes are not common and often associated with various syndromes. Review of the literature revealed only a few reported cases. Leslie ${ }^{14}$ reported of a 25year old black male with non-syndrome multiple impacted supernumerary teeth that resembled regular mandibulary premolar teeth. Yuce ${ }^{15}$ and Yusof $^{16}$ also reported similar cases in a young adult patient's maxilla and mandible. Yusof ${ }^{16}$ reviewed most of the cases reported in the English language literature from 1969 to 1990 and found that there was a predilection of non-syndrome multiple supernumerary teeth that occur in the mandible. However, in our patients (case 1 and 3) nine unerupted supernumerary teeth were noted, eight of them were in the maxillary and the other was in the mandible.

The frontal sinus is the only sinus that cannot be recognized radiologically in the neonate. The 
frontal diverticulum is present, but the frontal bone is not pneumatized until between the first and second years of life. The frontal sinus may assume its definite shape as early as the third year of life, but continued growth and development are carried well into puberty. The frontal sinus is capable of extremes of under and over development. Agenesis and massive pneumatization are both seen with regularity. ${ }^{17,18}$ Maxillary sinus hypoplasia is rare, with an estimated prevalence of $1-5 \% .{ }^{19,20}$ Occasionally the lumen of the maxillary sinus may be small and its bony walls thick as a result of incomplete pneumatization and development. Complete failure of development of the antral lumen and total absence of the maxillary sinus are rare. ${ }^{17,19}$ Rhinootolaryngologycal examination of our patient (case 2) revealed no pathological symptom. But CT scan of the paranasal sinus evaluations showed frontal sinus agenesis and maxillary sinus hypoplasia. Besides, an instance of physical trauma to the left frontal region during childhood and recurrent bronchitis were detected.

To achieve optimum function and aesthetics, an interdisciplinary cooperation between the oral surgeon, orthodontist, prosthodontist and pedodontist should be based for the management of the case. ${ }^{6}$

The concept of treatment of these cases contains serial examination of primary teeth, removal of the supernumerary teeth, assisting the eruption of the permanent teeth by orthodontic traction or surgical exposure and any impacted tooth which couldn't erupt after surgical or orthodontic methods needs extraction and replacement. 3,21

\section{REFERENCES}

1. Alling CC, Catone GA.Management of impacted teeth. $J$ Oral Maxillofac Surg 1993; 51(suppl 1):3-6.

2. Gorlin RJ, Cohen MM, Hennekam RCM. Syndromes of the Head and Neck Fourth Edition. Oxford University Press US; 2001.

3. Babu V, Nagesh KS, Diwakar NR. A rare case of hereditary multiple impacted normal and supernumerary teeth. J Clin Pediatr Dent 1998;23:59-62.

4. Cooper SC, Flaitz CM, Johnston DA, et al. A natural history of cleidocranial dysostosis. Am J Med Genet 2001;104:1-6.

5. Kirson LE, Scheiber RE, Tomaro AJ. Multiple impacted teeth in cleidocranial dysostosis. Oral Surg Oral Med Oral
Path 1982;54:604.

6. Sharma A. A rare non-syndrome case of concomitant multiple supernumerary teeth and partial anodontia. J Clin Pediatr Dent 2001;25:167-169.

7. Yalcın S, Gurbuzer B. Multiple impacted teeth in the maxilla. Oral Surg Oral Med Oral Pathol 1993;76:130.

8. Dayal PK, Chaudhary AR, Desai KI, et al. Aarskog syndrome. A case report. Oral Surg Oral Med Oral Pathol 1990;69:403405.

9. Chodirker BN, Chudley AE, Toffler MA, et al. ZimmermannLaband syndrome and profound mental retardation. Am J Med Genet 1986;25:543-547.

10. Bakaeen G, Scully C. Hereditary gingival fibromatosis in a family with the Zimmermann-Laband syndrome. J Oral Pathol Med 1991;20:456-459.

11. Mercuri LG, O'Neil R. Multiple impacted and supernumerary teeth in sisters. Oral Surg Oral Med Oral Pathol 1980;50:293.

12. Black SL, Zallen RD. An unusual case of multiple impacted teeth. Oral Surg Oral Med Oral Pathol 1974;37:975-976.

13. Finkel A, Solondz G, Friedman J. Multiple supernumerary and impacted teeth. Oral Surg Oral Med Oral Pathol 1974;37:976-977.

14. Leslie JC. Multiple supernumerary teeth. Oral Surg Oral Med Oral Pathol 1984;57:463.

15. Yucel E. Multiple supplemental premolars. Oral Surg Oral Med Oral Pathol 1992;74:384.

16. Yusof WZW, Awang MN. Multiple impacted supernumerary teeth. Oral Surg Oral Med Oral Pathol 1990;70:126.

17. Paparella MM, Shumrick, editors. DA.Otolalaryngology led 2). Philadelphia: WB Saunders Company; 1980. p. 1021.

18. Cummings CW, Fredrickson JM, Harker LA, Krause JC, Schuller DE, editors. Otolaryngology head and neck surgery. Toronto: CV Mosby Company; 1986. p. 845-849.

19. Plaza G, Ferrando J, Martel J, Toledano A, de los Santos G. Maxillary sinus hypoplasia. Acta Otorrinolaringol Esp 2001;52:122-128.

20. Kapoor PK, Kumar BN, Watson SD. Maxillary sinus hypoplasia. J Laryngol Otol 2002;116:135-137.

21. Yıldırım D, Yılmaz HH, Aydin U. Multiple impacted permanent and deciduous teeth. Dentomaxillofac Radiol 2004;33:133-135. 